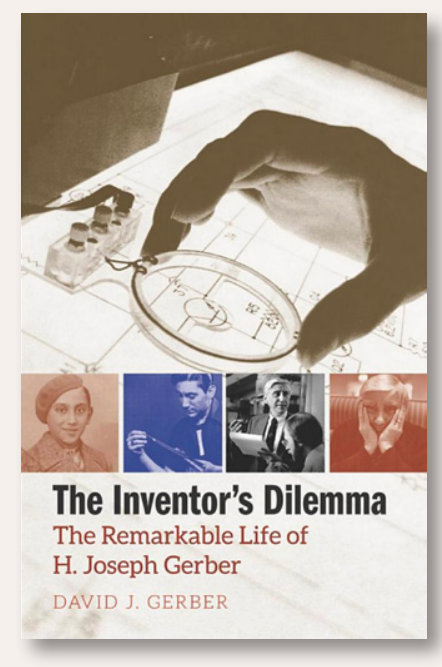

\section{THE INVENTOR'S DILEMMA: THE REMARKABLE LIFE OF H. JOSEPH GERBER}

\author{
By David J. Gerber
}

Yale University Press, 2015

400 pages

Hardcover: \$38.00, ISBN 978-0-300-12350-0

Review by: Russell S. Kirby, University of South Florida
WHEN FIRST ASKED IF I would be interested in reviewing this book, I wondered to myself, "Who was H. Joseph Gerber?" and "What did he have to do with cartography?" A quick internet search revealed thumbnail answers that led me to accept the review invitation: Gerber was a remarkable scientist, engineer, and entrepreneur, whose inventions literally set the stage for the advent of digital cartography. In fact, the Gerber Automatic Plotter and Reader was the first commercially available machine that could plot graphics digitally, and it is likely that his inventions in electrical engineering enabled the field of automated mapping to emerge several years earlier than it otherwise might have.

The book's title refers to a term coined in the 1990s by Clayton Christensen; an inventor's dilemma comes about when a disruptive innovation or invention creates new markets and displaces older technologies-often changing the business landscape in the process. Businesses face the dilemma of continuing to focus on products and services that customers need or can use now, versus developing or adopting technologies that will create or meet customer demands in the future. As recounted in this biography, Gerber had, on numerous occasions throughout his career, the perspicacity and vision to identify the opportunities presented by his innovations and technical developments, and the boldness to gamble that his customers would follow his lead—or that new customers would appear.

This book is at once both a biography of a remarkable scientist and entrepreneur, and a history of technological developments in engineering and computer peripherals in the latter half of the twentieth century. Written by Gerber's son, David J. Gerber, the narrative chronicles Gerber's life and work, as well as his legacy in the years following his death in 1998. Starting with his early years in pre-World War II Vienna, Austria, it follows his postwar transition to life as a refugee in the United States, and his development as an inventor and entrepreneur-including the history of the company he founded, Gerber Scientific. While the book is biographical in nature, this review focuses on those aspects of Gerber's career of special relevance to the fields of cartography and GIScience.

Joseph Gerber trained as an engineer, and developed several practical inventions while still a student. Beginning with the Gerber Variable Scale, he developed a series of mechanical computation devices for scientific and engineering applications, including the GraphAnalogue, the Derivimeter, and the Equameter. From the perspective of GIScience, Gerber is perhaps best known as the inventor of the digital plotter.

What set Gerber apart from many inventors was his interest in developing new tools and devices within the context of commercial processes-rather than as stand-alone inventions to be marketed in their own right-and he produced a series of new devices for specific purposes, including the automation of apparel and shoe manufacturing. His plotting devices, for example, were used to draw digital graphics onto film for the production of integrated circuit boards, using a photo-plotting method he developed. 
These tools and methods formed the basis for electronics fabrication, and led eventually to the advent of computer-aided design, or CAD, a field that Gerber Scientific pioneered.

Gerber neither invented GIS nor automated cartography, but it is hard to imagine these endeavors developing as they did without the devices he created or the insight he had into how technology could transform manufacturing processes. Nowadays, few cartographers or GIScientists use digital plotters, and technological advances in printing methods have rendered these devices largely - though not entirely-superfluous. From the 1970s into the 1990s these devices were ubiquitous anywhere computer cartography was done, and many larger laboratories and agencies still have a few set aside in case they may be needed. Even the large-format, high-resolution printers we use today to print maps and posters incorporate inventions patented by Joseph Gerber, if not in their works, then at least in their DNA. So, while Gerber would never have considered himself a GIS pioneer, the field we know today could not have come into being without his work.

The Inventor's Dilemma is part biography, part personal reminiscence on the part of its author, and part contribution to business history and the history of science. The book is very readable, with illustrations and photographs, notes, a bibliography, and an index. Those interested in the history of technology as it applies to the development of computer cartography and, eventually, of GIS may wish to read this book. Geography and map libraries may wish to acquire it, as most GIS professionals will likely prefer to borrow rather than own it. 